\title{
Research on Risk Early Warning of Integrated Energy Trading Market
}

\author{
Cheng Jiang ${ }^{1,2}$, Bin Yang ${ }^{3}$, Liangliang Zhu ${ }^{1,2}$, Wenjun Ruan ${ }^{3}$, and Zhenyu Wang ${ }^{4}$ \\ ${ }^{1}$ NARI GROUP CORPORATION/STATE GRID ELECTRIC POWER RESEARCH INSTITUTE, Nanjing 210000, China \\ ${ }^{2}$ STATE GRID ELECTRIC POWER RESEARCH INSTITUTE WUHAN EFFICIENCY EVALUATION COMPANY LIMITED, \\ Wuhan 430074 , China \\ ${ }^{3}$ State Grid Jiangsu Electric Power Company
}

\begin{abstract}
The advent of the energy Internet era has deepened the coupling between different energy sources. Energy conversion and storage components such as micro gas turbines, electricity-to-gas, and air source/ground source heat pumps have gradually become the mainstay of the integrated energy market. During the construction of China's integrated energy trading market, various risks will be faced inevitably. In order to promote the sustainable and healthy development of the market, risk early warning research is particularly important. The normal operation of the integrated energy trading market can be guaranteed by early warning of the risk state of the market and timely adoption of corresponding countermeasures to control risks. This article first combed the concepts of integrated energy services and integrated trading market, and pointed out the important position of the integrated energy trading market in the energy and national economic system. Secondly, it identifies the risk factors that affect the security of China's integrated energy trading market. Then, an effective method for predicting the risk of China's integrated energy trading market is constructed through the fuzzy risk early warning method. Finally, corresponding countermeasures and suggestions are put forward for risk management of China's integrated energy trading market.
\end{abstract}

\section{Introduction}

In recent years, China has proposed the "Internet $+"$ smart energy plan, which described the vision of the future energy internet, and pointed out that full consideration of the coupling between different forms of energy such as electricity, heat, and gas is an important foundation for building the energy internet. Among them, the analysis and research on the risks that exist in the construction of the integrated energy trading market play an important role. Based on the characteristics and requirements of the integrated energy trading market, we can build a risk warning model, regularly conduct risk warnings, and diagnose market development conditions, which can promote the continuous improvement and sustainable and healthy development of the market.

At present, there are many researches on the identification and early warning of power market operation. Literature [1] established an evaluation index system based on language-based fuzzy analytic hierarchy process to realize the identification of the importance of the power market operation management risk. Literature [2] based on the theory of project risk management, designs a system construction project risk identification and evaluation method. Literature [3] analyzes the research status of risk-oriented auditing from different perspectives in the theoretical and practical circles, and proposes a dual-source risk identification method and a risk-oriented analysis model based on audit data. Literature [4] proposes the concept of a marketing business service risk index to measure the risk of marketing business services.

As the integrated energy trading market is an emerging market, it is in its infancy and lacks a corresponding market risk early warning mechanism.

Therefore, relevant research is needed. Through early warning of the risk state of this market, corresponding countermeasures can be taken in time to control risks, so as to ensure the normal operation of the integrated energy trading market and provide a guarantee for economic and social development.

This paper first identifies the risk factors that affect the security of the integrated energy trading market. Then, the fuzzy risk early warning model is used to construct the risk early warning model of China's integrated energy trading market, and an effective method for predicting risks is proposed. Finally, corresponding countermeasures and suggestions are put forward for the risk management of the integrated energy trading market.

\section{Integrated energy trading market}

The energy industry is currently undergoing a series of major changes and innovations. Only by understanding

\footnotetext{
* Corresponding author: 271192468@qq.com
} 
them can we grasp the true meaning and boundaries of many concepts.

\subsection{The integrated energy service}

Integrated energy service is a new type of energy service method to meet the diversified energy production and consumption of customers. On the energy supply side, wind, light, coal, oil, gas, electricity and other energy sources are developing in the direction of comprehensive optimization, and synergistic effects are beginning to appear. On the energy consumption side, traditional independent energy supply methods such as power supply, gas supply, water supply, and heating supply are blurring boundaries and moving towards integration.

The most essential feature of the integrated energy service is that it takes the power system as the core and changes the existing mode of independent planning, design and independent operation of various energy supply systems such as power supply, gas supply, cooling and heating. It uses modern physical information technology, intelligent technology and management models to organically coordinate and optimize the distribution, transformation, storage, and consumption of various energy sources in the process of planning, design, construction and operation. Most importantly, it plays the role of a new regional energy supply system that makes full use of renewable energy.

The future development of integrated energy services will be towards the direction of diversified energy supply, diversified services, diversified energy use methods and more intelligent.

\subsection{The integrated energy trading market}

For multiple energies of cold, hot and electric, if only a single energy supply system is considered and the design and operation are planned separately, it will not be conducive to the improvement of energy efficiency. Therefore, based on the separate operation of each system in the past, we comprehensively consider the supply and demand of multiple energy sources, coupling the electricity market, natural gas market, and cold and heat markets together, and consider the mutual transformation of energy. In this way, a integrated energy trading market will be constructed to organically coordinate and optimize the distribution, transformation, storage, and consumption of various energy sources, and improve energy utilization efficiency.

The integrated energy trading market is a virtual market in which multiple energy transaction results are formed through integrated transactions in various markets, and then executed by each market. In the integrated energy trading market, users and energy suppliers take into account coupling characteristics and directly trade in the electricity market, natural gas market, and cold and hot markets. Therefore, the integrated energy trading market actually contains two meanings: integrated energy supply and integrated energy service.

\subsection{Development status of China's integrated energy trading market}

According to the 2020 Electric Power Industry Development Report, China's energy internet construction has accelerated in 2019, and the level of terminal energy electrification has improved. The continuous reform of the electric power system has gradually accelerated the technological innovation of electric power and achieved results in standardization. At the same time, the construction of a global energy internet has become a global consensus, and international cooperation in electric power has been further deepened.

In the Jiangsu Industrial Park, natural gas distributed combined heating, power and cooling is used to complete the tiered utilization of resources, and the energy comprehensive rate reaches about $70 \%$. At Peking University, through monitoring platform management, 22,500 tons of water and 1.16 million kilowatts of electricity can be saved every year. In Shanghai, Pudong Power Supply Company used the cloud platform to carry out load valley filling, which reduced the power load of the whole region by about $4 \%$. A lot of data shows that integrated energy management has changed the rhythm of energy use and brought new vitality to the region.

\section{Construction of risk early warning model in integrated energy trading market}

In order to fully grasp the risk information of the integrated energy trading market and control its development trend, so as to respond to various emergencies in a timely and effective manner, the establishment of a risk early warning model for the integrated energy trading market is indispensable, which is also the need to ensure national energy security and implement energy strategies.

\subsection{Identification of risk factors}

The risk identification analysis framework of the integrated energy trading market is constructed based on the external environment and the internal market. Through combing and analyzing the risk points of the integrated energy market, the risks of policy, market construction, technology, safety and management are clarified.

(1) External environment

The environmental risks of the integrated energy trading market are reflected in government policies and economic environment.

(2) Market quality

The quality risks of the integrated energy trading market are reflected in the current market level, market development speed, market stability and market efficiency.

(3) Technical risk 
The technical risk is one of the main risks faced by the current integrated energy trading market, which mainly focuses on the research and development of core technologies. It includes two indicators of technological development maturity, technical standard formulation and intellectual property protection.

(4) Security risk

The security risk of the integrated energy trading market is embodied in two aspects: data management risk and information security risk.

(5) Manage risk

The management risk of the integrated energy trading market is embodied in three aspects: organizational management risk, human resource quality risk and financial management risk.

\subsection{Determination of risk assessment index system}

On the basis of the above-mentioned main risk factors, several sub-elements are selected from each field to form an index system. The risk warning index system of the integrated energy trading market is shown in the following table.

Table 1. The risk warning index system of the integrated energy trading market

\begin{tabular}{|c|c|c|}
\hline $\begin{array}{c}\text { Evaluation } \\
\text { object }\end{array}$ & $\begin{array}{l}\text { Evaluation } \\
\text { dimension }\end{array}$ & sub-elements \\
\hline \multirow{13}{*}{$\begin{array}{l}\text { Risk early } \\
\text { warning of } \\
\text { integrated } \\
\text { energy } \\
\text { trading } \\
\text { market A }\end{array}$} & \multirow{2}{*}{$\begin{array}{c}\text { External } \\
\text { environment } \\
\text { B1 }\end{array}$} & government policies $\mathrm{C} 1$ \\
\hline & & economic environment $\mathrm{C} 2$ \\
\hline & \multirow{4}{*}{$\begin{array}{c}\text { Market } \\
\text { quality B2 }\end{array}$} & the current market level C3 \\
\hline & & $\begin{array}{c}\text { market development speed } \\
\text { C4 }\end{array}$ \\
\hline & & market stability C5 \\
\hline & & market efficiency C6 \\
\hline & \multirow[t]{2}{*}{$\begin{array}{l}\text { Technical } \\
\text { risk B3 }\end{array}$} & $\begin{array}{l}\text { technological development } \\
\text { maturity C7 }\end{array}$ \\
\hline & & $\begin{array}{c}\text { technical standard } \\
\text { formulation and intellectual } \\
\text { property protection } \mathrm{C} 8\end{array}$ \\
\hline & \multirow{2}{*}{$\begin{array}{c}\text { Security risk } \\
\text { B4 }\end{array}$} & data management risk C9 \\
\hline & & $\begin{array}{l}\text { information security risk } \\
\text { C10 }\end{array}$ \\
\hline & \multirow[t]{3}{*}{$\begin{array}{l}\text { Manage risk } \\
\text { B5 }\end{array}$} & $\begin{array}{c}\text { organizational management } \\
\text { risk } \mathrm{C} 11 \\
\end{array}$ \\
\hline & & $\begin{array}{l}\text { human resource quality risk } \\
\mathrm{C} 12\end{array}$ \\
\hline & & $\begin{array}{l}\text { financial management risk } \\
\qquad 13\end{array}$ \\
\hline
\end{tabular}

\subsection{Construction of early warning model}

At present, the fuzzy evaluation method has been widely used in the risk warning problem, and has achieved good research results. This paper uses the established risk early warning indicator system and fuzzy mathematics to construct a risk early warning model of integrated energy trading market.

\subsubsection{Fuzzy risk early warning model}

In recent years, fuzzy mathematical methods are often used for risk identification and early warning of a specific system or machine. It is expected to be applied to the overall risk management process of identificationrisk and evaluation-risk early warning, forming a scientific management system with risk early warning as the core. The modeling process is as follows:

(1) Determining the comment set V

Under a certain evaluation index system, the evaluation value is given to the evaluation object, which is recorded as $V=\left(V_{1}, V_{2}, \cdots, V_{m}\right)$. Among them, $(k=1,2, \cdots, m)$ represents reviews from high to low, such as using five-level reviews of "best, excellent, good, medium, and poor".

(2) Determining the fuzzy evaluation matrix

$R_{i}$ is a fuzzy mapping from the factor set to the comment set $\mathrm{V}$, where ${ }^{r_{i j k}}$ represents the degree of membership from the sub-element $j$ in factor $U_{i}$ to the comment $V_{k}$. The value method of $r_{i j k}$ is: statistically sorting out the scoring results of each expert, then obtaining sub-element $v_{i j k}$.

$$
r_{i j k}=v_{i j k} / \sum_{k=1}^{m} v_{i j k}
$$

Then getting fuzzy evaluation matrix $R_{i}$ :

$$
R_{i}=\left[\begin{array}{cccc}
r_{i 11} & r_{i 12} & \cdots & r_{i 1 m} \\
\vdots & \vdots & \ddots & \vdots \\
r_{i l 1} & r_{i l 1} & \cdots & r_{i l m}
\end{array}\right]
$$

Among them, $l$ means that there are ${ }^{l}$ sub-elements in factor $U_{i}$.

(3) Fuzzy risk early warning

Starting from the sub-elements, we can use the weight vector $\lambda_{i}=\left(\lambda_{i 1}, \lambda_{i 2}, \cdots, \lambda_{i l}\right)$ given by the mandatory determination method to obtain the membership vector $A_{i}$ of the main factor $U_{i}$ to the comment set $\mathrm{V}$.

$$
A_{i}=\lambda_{i} R_{i}
$$

Among them, $\lambda_{i l}$ represents the mandatory weight of the $l$ sub-element in the main factor $U_{i}$.

In the same way, the main factor weight vector $\lambda=\left(\lambda_{1}, \lambda_{2}, \cdots, \lambda_{n}\right)$ given by the mandatory determination method is used to obtain the membership vector $A$ of 
the risk in integrated energy trading market to the comment set $\mathrm{V}$.

$$
A=\lambda R
$$

Where $\lambda_{n}$ represents the mandatory weight coefficient of the main factor $n, R=\left(A_{1}, A_{2}, \cdots, A_{n}\right)^{T}$.

According to the principle of maximum degree of subordination, the risk status of China's integrated energy trading market can be analyzed.

\subsubsection{Early warning evaluation and results}

This paper adopts a five-level comment system, the comment set $\mathrm{V}=$ \{double green lights, green light, yellow light, red light, double red lights $\}$. By inviting 10 experts to evaluate each sub-element according to the above comment set, a fuzzy evaluation matrix is obtained, and the final solution is:

$A=\lambda R=(0.0660,0.2257,0.3054,0.2697,0.1332)$

It can be seen that the current risk status of China's integrated energy trading market is yellow light. This is because the current market is in a period of incubation, with insufficient technology and talent reserves, facing outstanding technical risks and management risks. Therefor, it is necessary to speed up relevant work such as technology research and development, professional talent recruitment and training.

\section{Risk management countermeasures of China's integrated energy trading market}

The integrated energy trading market involves many risk factors. In order to grasp the main aspects of the contradiction, the following countermeasures and suggestions are put forward based on the research of each influencing factor in the identification of risk factors.

(1) Policy level

The market members should closely follow up and study new policies, and formula response plans in a timely manner. In addition, actively guiding the improvement and adjustment of relevant laws and regulations on the integrated energy trading market is also inevitable.

(2) Market construction level

It is vital to improve the operating system and establish the management of market monitoring indicators. By accelerating the research on the operation mode of the integrated energy trading market, we can form a standardized market operation mechanism.

(3) Technical security level

Speeding up breakthroughs in core technologies and strengthening technological innovation is the current main job. At the same time, a dedicated data governance organization should be built to protect the interests and privacy of users.

\section{Conclusion}

This paper first sorts out the concepts of integrated energy service and integrated trading market, describes the current situation of the integrated energy trading market, and points out the important position of integrated energy trading market in the energy and national economic system. Secondly, the risk factors affecting the security of the integrated energy trading market were identified, and a risk early warning indicator system for the integrated energy trading market was constructed. Then we build a fuzzy risk early warning model based on the above indicator system, and propose a possible way to predict risk. Finally, corresponding countermeasures and suggestions are put forward for the risk management of integrated energy trading market.

The model constructed in this paper has certain applicability, and the predicted results are more consistent with the current market development status, which can provide security risk early warning and security guarantee for the market development. This provides a feasible solution for the risk early warning of the integrated energy trading market with positive theoretical and practical significance.

\section{Acknowledgement}

The State Grid Corporation Headquarters Science and Technology Project "Research on Supporting Technology of Integrated Energy Market Operation and Service Based on Value Sharing" (5400-202018202A-00-00).

\section{References}

1. Li Z.F., Shi H., Wu J.Y., Wang M., Wang D.X. (2019) HFLTS-AHP-based power market operation management risk identification. J. Control Engineering, 26(05): 1003-1010.

2. Lin Y.F., Xie H., Huang G., Yan C.Y., Peng Y. (2016) Research on Risk Management of Information Communication System Construction Projects in Electric Power Industry. J. Modern Electronic Technology, 39(23): 111-115.

3. Meng Q.L., Dai F.F., Zhang Y.X. (2018) Operational risk-oriented internal audit strategy and practice: taking state-owned power grid companies as an example. J. Finance and Accounting Newsletter, (31): 83-86+129.

4. He W.M., Zou Y.F., Wang L.Y. (2016) Research on the risk of electric power marketing services from the perspective of customers. J. Modern Electronic Technology, 39(15): 123-126. 